\title{
A study of microbiological analysis and its sensitivity pattern of postoperative wound infections in obstetrics and gynecology department: retrospective study in tertiary institute in Mangalore, Karnataka, India
}

\author{
Pramodha Mallik Shagun, Chaitra S.*
}

Department of Obstetrics and Gynecology, AJ Institute of Medical Science and Research Centre Mangalore, Karnataka, India

Received: 02 March 2020

Accepted: 16 March 2020

\author{
*Correspondence: \\ Dr. Chaitra S., \\ E-mail: cha199224@yahoo.com
}

Copyright: (C) the author(s), publisher and licensee Medip Academy. This is an open-access article distributed under the terms of the Creative Commons Attribution Non-Commercial License, which permits unrestricted non-commercial use, distribution, and reproduction in any medium, provided the original work is properly cited.

\begin{abstract}
Background: Infections acquired in hospitals are classified as nosocomial infections. Most of these infections are related to surgery, usually at the post-operative wound site. It is also termed Surgical Site Infection (SSI). Staphylococcus aureus is the documented most common organism that infect surgical wounds. This study was focused on identifying the most common microorganism documented in post-operative wound sepsis in abdomen hysterectomy surgery of obstetrics and gynaecology in a tertiary hospital in Mangalore. The aim of this study was to identify postoperative infection and to determine their current antimicrobial resistance to commonly prescribed drugs. Methods: Materials and Methods: This retrospective research was carried out in tertiary hospital with a sample size of 90 wound samples, whose records span from Jan 2014-Jan 2018. The study involved obtaining records of subjects with cases of contamination and isolation of organisms that frequently infect post-operative wound site in abdomen hysterectomy surgery.

Results: A total of 79 bacterial isolates were obtained from 95 wound culture samples. In 41 cases, the isolated culture were mono microbial, 39 cultures were polymicrobial whereas no growth was obtained in 15 cases. The results showed that Staphylococcus Aureus was the most frequently isolated organism (48.1\%), followed by Pseudomonas aeruginosa (18.98\%) and E. coli $(17.72 \%)$.

Conclusions: The study is therefore important in identifying those at risk of post-operative wound sepsis and the probable causative organisms. This will be useful in the choice of prophylactic antibiotics for treatment of high-risk patients, thereby setting up an empirical antibiogram for use.
\end{abstract}

Keywords: Polymicrobial, Postoperative, Surgical site infection

\section{INTRODUCTION}

World Health Organization (WHO) describes hospital acquired infections to be one of the major infectious diseases having a huge economic impact worldwide. ${ }^{1}$ These infections affect about 2 million people annually resulting in $5 \%$ to $15 \%$ of them requiring hospitalization. ${ }^{2,3}$
Nosocomial infection constitutes a major public health problem worldwide today. SSI are the second most common nosocomial infections. ${ }^{4}$ These remain a complication of surgical procedure resulting in increased morbidity, mortality and cost. $^{5}$ One of the major problems faced by patients in now a day is to deal with the post-surgical infections, as most of these are being caused by multiple drug resistant bacteria. ${ }^{6}$ 
A system of classification of SSI for operative wounds that is based on the degree of microbial contamination was developed by the US National Research Council group in $1964 .^{7}$

- Class 1 - Clean wounds

- Class 2 - Clean-contaminated wounds

- Class 3 - Contaminated wounds

- $\quad$ Class 4 - Dirty wounds.

Depending on the class the chances of wound infection varies. ${ }^{8}$ Wound classification is well documented risk factors for SSI. ${ }^{9}$

The aim of this study was to identify the most common microorganism documented in post-operative wound sepsis in abdominal hysterectomy in tertiary hospital in Mangalore, Karnataka, India.

\section{METHODS}

This is a retrospective study done over a period of four years in a tertiary care hospital in Mangalore, on patients undergoing, total abdominal hysterectomy who had superficial wound dehiscence (skin and subcutaneous tissue).

\section{Inclusion criteria}

- All patients who underwent total abdominal hysterectomy with superficial wound dehiscence.

\section{Exclusion criteria}

- Patients who did not come under the above criteria as per the CDC guidelines.
Following criteria were used to diagnose SSI, wound dehiscence or febrile morbidity

- Febrile morbidity - this was defined as febrile episodes of $>38^{\circ} \mathrm{C}$, occurring on two occasions, at least 4 hours apart, after 24 hours following the operation

- Surgical site infection - this was defined as (a) erythema and or induration (b) serous oozing (c) the presence of pus

- Wound dehiscence - separation of edges of suture line by more than $1 \mathrm{~cm}$ - superficial or deep as per CDC guidelines.

\section{Statistical analysis}

Data related outcome variables age, body mass index, associated risk factors, indication of surgery, nature of surgery, technique of surgery, duration of surgery, duration of anesthesia, intraoperative complications, infective morbidity, surgical site infections and wound related complications was collected. Information was collected in structured proforma and then entered in Microsoft office excel sheet for analysis using statistical package for the social sciences (SPSS) version 16. Continuous variables were expressed as mean $\pm \mathrm{SD}$, categorical variables were expressed as frequencies and percentages and t-test was applied to find the association between different variables. p value less than 0.05 were considered significant.

\section{RESULTS}

Total abdomen hysterectomy done in the specified period were 500. Total no. of wound dehiscence were 90 (18\%).

Table 1: Type of surgery and frequency of SSI distribution among the study population.

\begin{tabular}{|llll|}
\hline Type of surgery & No. of cases & Frequency of wound infection & Percentage \\
\hline TAH+ BSO & 500 & 90 & $18 \%$ \\
\hline Others (Laparotomy) & 100 & 5 & $5 \%$ \\
\hline
\end{tabular}

Table 2: Based on BMI (body mass index) of patient following data was obtained.

\begin{tabular}{|c|c|c|c|}
\hline & Underweight $\left(<18.5 \mathrm{~kg} / \mathrm{m}^{2}\right.$ ) & Normal $\left(18.5-25 \mathrm{~kg} / \mathrm{m}^{2}\right)$ & Obese $\left(>25 \mathrm{~kg} / \mathrm{m}^{2}\right)$ \\
\hline TAH+BSO $(n=90)$ & $9(10 \%)$ & $36(40 \%)$ & $45(50 \%)$ \\
\hline
\end{tabular}

The mean age of the patients in the study was $36.69 \pm 13.54$ years. Wound infection rate was higher among 20-34 years age group (17.39\%).

Most women with wound dehiscence were from the lower socioeconomic strata as seen in Table 3.

Preoperative haemoglobin was measured and those who anemic had higher rates of wound dehiscence.
Preoperative anemia is a major predictor of impending surgical morbidity as seen in Table 4.

Associated medical disorders increased the chances of wound dehiscence.

Out of 500 TAH, 100 had diabetes mellitus and out of which 90 dehiscence. Good general health is necessary for wound healing 
Table 3: Socio economic status based on modified Kuppuswamy classification.

\begin{tabular}{|ll|}
\hline Socio economic status & Numbers \\
\hline Upper socio-economic strata & $20(22.22 \%)$ \\
\hline Middle socio-economic strata & $25(27.77 \%)$ \\
\hline Lower socio-economic strata & $45(50 \%)$ \\
\hline
\end{tabular}

There was no significant correlation between history of previous abdominal surgery and wound dehiscence as seen in Table 5 below.

\section{Table 5: History of previous abdominal surgery.}

\begin{tabular}{|lll|}
$\begin{array}{l}\text { History of previous } \\
\text { abdomen surgery in patients } \\
\text { with scar dehiscence }\end{array}$ & Yes & No \\
$\begin{array}{lll}\text { Percentage of patient with } \\
\text { wound dehiscence }\end{array}$ & 30 & 60 \\
\hline
\end{tabular}

Duration of surgery was estimated. Surgery in inexperienced surgeons (e.g.: trainees in teaching hospitals) tend to take longer increasing the chance of wound-dehiscence as seen in Table 6.

A total of 79 bacteria were isolated from 90 swab specimens collected from post-operative wound infection. Monomicrobial growth was seen in 40(50.63\%) samples followed by polymicrobial growth was seen in 39 (49.36\%) samples. Staphylococcus aureus (48.1\%) was the predominant bacteria isolated. E. coli $(17.72 \%)$ and pseudomonas aeruginosa $(18.98 \%)$ were second predominant bacteria isolated. Staphylococcus aureus is the predominant organism infecting the hysterectomy surgery as seen in Table 7.

Table 7, represents the name of organisms with its percentage of occurrence. The most common pathogen present in post-operative wound infection was viz., Staphylococcus aureus $(48.1 \%)$ followed by Pseudomonas aeruginosa (18.98\%), E. coli $(17.72 \%)$ and Staphylococcus epidermidis (10.1\%).

Table 6: Time taken for the surgery and its association with wound dehiscence.

\begin{tabular}{|ll|}
\hline $\begin{array}{l}\text { Time taken for surgery in patients } \\
\text { with wound dehiscence }\end{array}$ & $\begin{array}{l}\text { No. of } \\
\text { patients }\end{array}$ \\
\hline$<2$ hours & $12(13.33 \%)$ \\
\hline$>2$ hours & $78 .(86.66 \%)$ \\
\hline
\end{tabular}

Table 7: List of bacterial isolates recovered from postoperative wound.

\begin{tabular}{|lll|}
\hline Name of organism & $\begin{array}{l}\text { No. of } \\
\text { organisms }\end{array}$ & Percentage \\
\hline Staphyloccocal aureus & 38 & $48.1 \%$ \\
\hline S. Epidermidis & 8 & $10.1 \%$ \\
\hline E. Coli & 14 & $17.72 \%$ \\
\hline Proteus mirabilis & 3 & $3.79 \%$ \\
\hline Pseudomonas aeruginosa & 15 & $18.98 \%$ \\
\hline Enterobacter species & 1 & $1.26 \%$ \\
\hline Total & $\mathbf{7 9}$ & $\mathbf{1 0 0 \%}$ \\
\hline
\end{tabular}

Table 8: Antibiotic susceptibility pattern in wound culture isolates.

\begin{tabular}{|c|c|c|c|c|c|c|c|c|c|c|c|c|c|c|}
\hline \multirow[b]{2}{*}{ Antibiotics } & \multicolumn{2}{|c|}{ 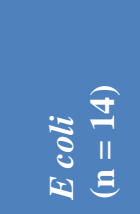 } & \multicolumn{2}{|c|}{ 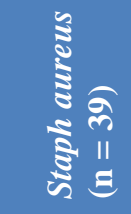 } & \multicolumn{2}{|c|}{ 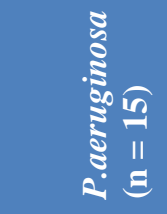 } & \multicolumn{2}{|c|}{ 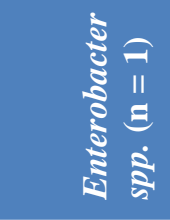 } & \multicolumn{4}{|c|}{ 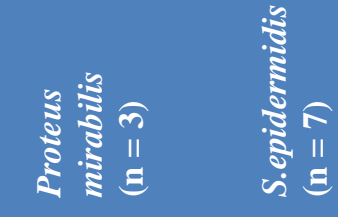 } & \multicolumn{2}{|c|}{ 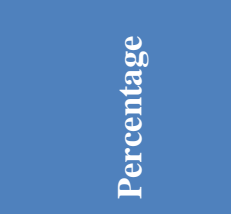 } \\
\hline & $\mathbf{S}$ & $\mathbf{R}$ & $\mathbf{S}$ & $\mathbf{R}$ & $\mathbf{S}$ & $\mathbf{R}$ & $\mathbf{S}$ & $\mathbf{R}$ & $\mathbf{S}$ & $\mathbf{R}$ & $\mathbf{S}$ & $\mathbf{R}$ & $\mathbf{S}$ & $\mathbf{R}$ \\
\hline Penicillin & 12 & 2 & 39 & 0 & 15 & 0 & 1 & 0 & 3 & 0 & 7 & 0 & $97.4 \%$ & $2.5 \%$ \\
\hline Carbapenem & 14 & 0 & 39 & 0 & 15 & 0 & 1 & 0 & 3 & 0 & 7 & 0 & $100 \%$ & $0 \%$ \\
\hline Quinolones & 8 & 6 & 39 & 0 & 7 & 8 & 1 & 0 & 3 & 0 & 7 & 0 & $82.2 \%$ & $17.7 \%$ \\
\hline Monobactem & 11 & 3 & 28 & 11 & 7 & 8 & 1 & 0 & 3 & 0 & 7 & 0 & $72.1 \%$ & $27.8 \%$ \\
\hline Cephalosporins & 5 & 9 & 11 & 28 & 8 & 7 & 0 & 1 & 0 & 3 & 0 & 7 & $30.3 \%$ & $69.6 \%$ \\
\hline Aminoglycoside & 7 & 7 & 39 & 0 & 12 & 3 & 1 & 0 & 2 & 1 & 0 & 7 & $77.2 \%$ & $22.7 \%$ \\
\hline Macrolides & 0 & 14 & 11 & 28 & 0 & 15 & 0 & 1 & 0 & 3 & 0 & 7 & $13.9 \%$ & $86.0 \%$ \\
\hline Lincomycin & 0 & 14 & 25 & 14 & 0 & 15 & 0 & 1 & 0 & 3 & 0 & 7 & $31.6 \%$ & $68.3 \%$ \\
\hline Others & 0 & 14 & 0 & 39 & 0 & 15 & 0 & 1 & 0 & 3 & 0 & 7 & $0.05 \%$ & $100 \%$ \\
\hline
\end{tabular}

Table 8 revealed the sensitivity pattern of isolated and identified organisms, with their percentage occurrence of sensitivity and resistance against each antibiotic. The sensitivity patterns define that the higher sensitivity percentage was given by carbapenem $(100 \%)$, penicillin and its derivatives (97.4\%), quinolones (82.2\%), 
aminoglycosides (77.2\%) whereas the maximum resistance was given by fosfomycin, fusidic acid, cetaperazone $(100 \%)$, macrolides $(86 \%)$ and cephalosporins $(69.6 \%)$.

\section{DISCUSSION}

Wound dehiscence is multi-factorial. Major risk factors as per this study include obesity, malnutrition, low socioeconomic status, anemia, diabetes mellitus, prolonged surgery most of which cannot be influenced by the surgeon. Study can derive that prevention is primary for reducing incidence of wound dehiscence. A good diet with education to maintain hygiene and early correction of anemia and diabetes will definitely help in bringing down the rate of dehiscence. Proper surgical attire, hand washing and theatre sterility are also important. Correct surgical techniques like removing all devitalized tissue, maintaining effective homeostasis, gentle handling of tissues, eradicating dead space, avoiding inadvertent entries into a viscous, using drains and suture material appropriately.

In this study the frequently isolated organism was Staphylococcus aureus. In the nosocomial infection national surveillance service (NINSS) survey (1997 2001) which report Staphylococcus (47\%) including of methicillin resistant Staphylococcus aureus (MRSA) and Staphylococcus epidermidis (Coagulase Negative) as the most common organism which is responsible for causing SSI. $^{8}$

While considering sensitivity patterns, all strain of pathogenic microorganism is highly sensitive against carbapenem (imipenem, meropenem), penicillin derivatives (pipracillin/ tazobactum). Study also found that Staphylococcus aureus is $100 \%$ sensitive to glycopeptides (Vancomycin), a finding that is identical to other national studies.9-11 Pseudomonas also showed a maximum sensitivity to penicillin derivatives (Pipracillin/ Tazobactum) in this study and is already reported. ${ }^{8,12}$ Third generation Cephalosporin (ceftazidime) and Aminoglycoside (gentamycin) has a potent antipseudomonas activity. ${ }^{13}$ The antibiotic sensitivity of other isolates showed a variable pattern of resistance and susceptibility.

This study gives us an insight to the current state of causative pathogens and their sensitivity from superficial incisional SSI in study hospital. The surgeon, pharmacist, epidemiologist and microbiologist, have to take their local infecting organism/sensitivity pattern into account when formulating prophylaxis as well as empirical therapy guideline for individual surgical site. The chosen antibiotic must have antimicrobial susceptibility for the common prevalent stains of microorganisms.

Funding: No funding sources
Conflict of interest: None declared

Ethical approval: The study was approved by the Institutional Ethics Committee

\section{REFERENCES}

1. Naik G, Deshpande S. A study on surgical site infections caused by staphylococcus aureus with a special search for methicillin-resistant isolates. J Clin Diagnost Res. 2011;5:502-8.

2. Avalos-Bock S. Knocking out nosocomial infections. Nurs. 2019;34(11):24-5.

3. Anusha S, Vijaya LD, Pallavi K, Manavalan R. An epidemiological study of surgical wound infections in a surgical unit of tertiary care Teaching Hospital. Indian J Phar Pract. 2010;4:8-13.

4. Biadglegne F, Abera B, Alem A. Bacterial isolates from wound infection and their antimicrobial susceptibility pattern in Felege Hiwot Referral Hospital, North West Ethiopia. Ethiop J Health Sci. 2009;19:173-7.

5. Insan NG, Payal N, Singh M, Yadav A, Chaudhary BL, Srivastava A. Post-operative wound infection: bacteriology and antibiotic sensitivity pattern. IJCRR. 2013;5(13):74-9.

6. Raza M, Ranabhat A. Antimicrobial susceptibility patterns of the bacterial isolates in post-operative wound infections in a tertiary care hospital, Kathmandu, Nepal. Open J Med Microbiol. 2013;3:159-63.

7. Schwartz SI, Comshires G, Spencer FC, Dally GN, Fischer J, Galloway AC. Principles of surgery. 9th edition. Chapter 6L: surgical infections. NY: McGrawHill companies; 2010.

8. Gautam R, Acharya A, Nepal HP, Shrestha S. Antibiotic susceptibility pattern of bacterial isolates from wound infection in Chitwan Medical College Teaching Hospital, Chitwan, Nepal. IJBAR. 2013;4(4):248-52.

9. Bessa LJ, Fazii P, Giulio MD. Bacterial isolates from infected wounds and their antibiotic susceptibility pattern: some remarks about wound infection. Int. Wound J. 2015;12(1):47-52.

10. Manikandan C, Amasth A. Antibiotic susceptibility of bacterial strains isolated from wound infectionpatients in Pattukkottai, Tamil Nadu, India. Int J Curr Microbiol App Sci. 2013;2(6):195-203.

11. Anil K. Study and use of antimicrobials in postoperative wound infections in gastrointestinal surgeries. Indo Am J Pharm Res. 2013;3:4.

12. Amoran OE, Sogebi AO, Fatugase OM. Rates and risk factors associated with surgical site infections in a tertiary care center in South-Western Nigeria. Int J Trop Dis Health. 2013;3(1):25-36.

13. Majeed MT, Izhar M. Glycopeptides sensitivity pattern in staphylococci isolated from clinical specimens in a tertiary care hospital. Ann KE Med Coll. 2015;11:26371.

Cite this article as: Shagun PM, Chaitra S. A study of microbiological analysis and its sensitivity pattern of postoperative wound infections in obstetrics and gynecology department: retrospective study in tertiary institute in Mangalore, Karnataka, India. Int J Reprod Contracept Obstet Gynecol 2020;9:1784-7. 